\title{
Interleukine-33 and Lipid Profile in Cardiovascular Diseases Patients and Healthy Subjects
}

\author{
Dr. Muntaha Abass Lafta \\ Department of Chemistry, College of Education for Pure Sciences- Ibn-Alhaitham, Baghdad University, \\ Baghdad, Iraq \\ dr_muntahaabass@yahoo.com
}

\begin{abstract}
Interleukine-33 (IL-33), a newly described member of the IL-1 family, is expressed by many cell types, but the precise source of IL-33 remains so far unclear. IL-33 is implicated in the pathogenesis of many diseases. However, IL-33 is a multifaceted mediator with both pro- and anti- inflammatory activities, it presents an extracellular and nuclear - bound from, each of them performing distinct activities of their own.
\end{abstract}

The objective of the present study is to evaluate the serum level of IL-33 in patients suffering from diverse cardiovascular diseases (CVD) with different body mass index (BMI), and to compare those with healthy control subjects with matched BMI. In an attempt to find the contribution of IL-33 and obesity to the pathogenesis of cardiovascular diseases.

The study was carried on( 30) patients with cardiovascular diseases, who were divided to three equal groups according to their $B M I$ as $\mathrm{G}_{1}$ with BMI (20-24.9), $\mathrm{G}_{2}$ with $\mathrm{BMI}(25-29.9)$ and $\mathrm{G}_{3}$ with $\mathrm{BMI}>30$. Healthy individuals were included (10) for each patients group matched $\mathrm{BMI}$ and age. All subjects performed serum tests for lipid profile and IL-33 after an overnight fast.

The results showed a significant rise in total cholesterol and triglyceride only for G3 when compared to their healthy control, while significant differences were found for LDL, VLDL and IL-33 for all patient groups when compared with their matched age and BMI control groups. Also a significant elevation for G3 compared to G1 and G2 in triglyceride, LDL and IL33 were found.

A conclusion could be made that IL-33 and LDL are significantly affected by BMI in patients groups only and not in the control subjects. This confirms the synergistic effect of the obesity and cardiovascular events on IL-33, while no effect of the disease could be detected from the present study.

\section{Indexing terms/Keywords}

IL-33, obesity; lipid profile; cardiovascular disease.

Abbreviations: IL-33, Interleukin-33; CVD, Cardiovascular disease; BMI, body mass index.

\section{Council for Innovative Research}

Peer Review Research Publishing System

\section{Journal: Journal of Advances in Chemistry}

Vol. 7, No. 2

editor@cirworld.com

www.cirworld.com, member.cirworld.com 


\section{INTRODUCTION}

Cardiovascular disease (CVD) is a class of disease that involves the heart, blood vessels or both. Obesity is often linked to diseases that involve the heart, the blood vessels or both [1].

Obesity is the commonest nutritional disorder in affluent societies [2]. Obesity has become a leading health concern because this condition is a chronic, complex, multifactorial disease in which a person's weight is $\geq 20 \%$ of the ideal weight for a given height [3]. Although not a direct measure of obesity, the most widely used method to gauge obesity is the Body Mass Index (BMI) which is equal to Weight $/$ Height $^{2}$ in $\left(\right.$ Kilogram $/$ Meter $^{2}$ ). [4]

Intreleukine-33 (IL-33) is the latest accrual to the IL-1 cytokine superfamily. Although, this super family encompasses structurally related cytokines IL-1 $\alpha$, IL-1 $\beta, \mathrm{IL}-1 \mathrm{Ra}$ (IL-1 receptor antagonist), IL-18 and IL-33. IL-33, IL-1 $\beta$ and IL-18 are rated as primordial inflammatory cytokines, whereas IL-Ra is an anti-inflammatory peptide which dampens excessive activities of IL-1 $\beta$. IL-33, in its own turn, stands out as a cytokine with dual function. Through the activation of the ST2L membrane receptor complex it acts as a traditional conceived cytokine. [5]

Interleukine-33, the novel member of the IL-1 cytokine superfamily, was

suggested to take part in the anti-atherogenic response by mediating the Th1-to-Th2 switch of the immune reactions. However, IL-33 is multifaceted mediator with both pro- and anti- inflammatory activities, IL-33 presents both an extracellular (cytokine-like) and a nuclear - bound (transcription factor-like) from, each of them performing distinct activities of their own. [6]

However IL-33 has shown various protective effects in cardiovascular diseases such as atherosclerosis, obesity, type-2 diabetes and cardiac remodeling. Thus the effects of IL-33 are either pro-or-anti-inflammatory depending on the disease and the model [7]. The C-terminal fragment of IL-33 is the only cytokine that has been shown to bind the receptor ST2L. The IL-33/ST2L complex subsequently associates with 1L-receptor accessory protein (IL-1RAcP) thereby activating intracellular molecules in the nuclear factor-kB (NF-kB) and mitogen activated protein kinase (MAP kinase) signaling pathways. This activation derives the production of type2 cytokines from polarized Th2 cells. [8]

It has been shown that IL-33 expressed in various human tissues, particularly those which are in contact with environmental conditions, either external, or internal, but the most importantly that IL_33 expression has been documented in coronary artery endothelium, coronary artery smooth muscle cells, cardiac fibroblast and adipocytes. [9]

The aim of the present study was to evaluate serum interleukin-33 in normal weight and obese cardiovascular patients and healthy population, since obesity is one of the most important modifiable risk factors for cardiovascular disease (CVD).

\section{METHADOLOGY}

\section{Sampling}

Ten $\mathrm{ml}$ of venous blood was placed in a plain tube ( no anticoagulant), which was taken from groups attending, left for (15) at room temperature, then centrifuged (at $2500 \mathrm{rpm}$ for $10 \mathrm{~min}$ ) to get the serum, which was stored about $\left(-20^{\circ} \mathrm{C}\right.$ ) unless used immediately.

The samples were collected from cardiovascular patients their ages ranged between (33-67) years, at the diagnosis time at (Ibn- Albetar Specialized Hospital/Baghdad) during the period from December 2012 to April 2013.

None of the control were atherosclerotic vascular disease, diabetic, renal disease, history of allergy, alcoholic consumption and heavy smoker.

The samples have been classified into four groups as follow:

1-Control group: includes (10) healthy (both sex) for each group according to BMI, ages range (25-63) years and no previous diseases which may interfere with the parameters analyzed in the study.

2-Patients group were divided into three groups according to BMI:

A- Group (1): includes (10) patients (both sex) with BMI (20-24.9) $\mathrm{Kg} / \mathrm{m}^{2} \quad$ B- Group (2): includes (10) patients (both sex) with BMl (25-29.9) $\mathrm{Kg} / \mathrm{m}^{2} \quad$ C- Group (3): includes (10) patients (both sex) with BMl (30 to over) $\mathrm{Kg} / \mathrm{m}^{2}$

\section{METHODS}

\section{Lipid profile analysis:-}

-Fractions of serum lipids were performed using read kit from Bio Merieux A.S., France as follow:

-Serum total cholesterol was determined by the enzymatic method employing a series of enzymes (i.e. easterase, oxidase and peroxidase) according to the method of Richmond. [10]

-Serum triglyceride was determined colometrically by enzymatic method using a series of enzymes (i.e. lipase, glycerol kinase, glycerol-3-phosphate oxidase and peroxidase) [11] 
-Serum HDL was determined after precipitation of chylomicron, VLDL and LDL contained in the serum samples by addition of $4 \%$ phosphotungestic acid in the presence of magnesium chloride, the supernatant obtained after centrifugation contain the HDL which was determined according to Burstein, et.al.(1970).[12]

-Serum LDL was determined indirectly by the use of Friedwald Formula [13]

\section{Interleukine-33 (IL-33) determination:-}

Interleukine-33 has been estimated by using enzyme immunoassay (ELISA) technique using the manufacturer instruction as supplied with kit from Ray Bio® Human. [14]

Body Mass Index :-was calculated according to the relation:

Weight $(\mathrm{Kg}) /[\text { Height }(\mathrm{M})]^{2} \quad[15]$

Fost et.al suggested that BMl of (18.5-24.9) indicate a person of normal weight. A person with BMl of (25-29.9) is overweight, while a person with $\mathrm{BMI}$ of $>30$ is obese. [16]

The body mass index (BMI), or Quetelet index, is a measure for human body shape based on an individual's mass and height.

Devised between 1830 and 1850 by the Belgian polymath Adolph Quetelet during the course of developing "social physics", (15) it is defined as the individual's body mass divided by the square of their height- with the value universally being in units of $\mathrm{Kg} / \mathrm{m}^{2}$.

$\mathrm{BMI}=\operatorname{mass}(\mathrm{kg}) /[\text { height }(\mathrm{m})]^{2}$

\section{STATISTICAL ANALYSIS}

The results were expressed as Mean \pm SD. Student- test was used to show the differences between groups variation was considered significant when $P$ - values are $<0.05$. The correlation coefficient $(r)$ test is used to describe the association between the different studied parameters.

\section{RESULTES}

In table (1) there were no significant differences between mean \pm SD values of patient groups and their control in HDL $\mathrm{P}>0.05$, but there were a significant differences in total cholesterol and triglyceride only for G3 and their control. On the other hand significant differences were found for all studied groups with their control for LDL, VLDL and IL-33.

For the other part of the same table, there were a significant differences for G3 compared to G1 and G2 in triglyceride, LDL and IL-33.

Table (1): All parameters involved in the study for all patient groups and control groups (Mean $\pm S D)$ according to BMI

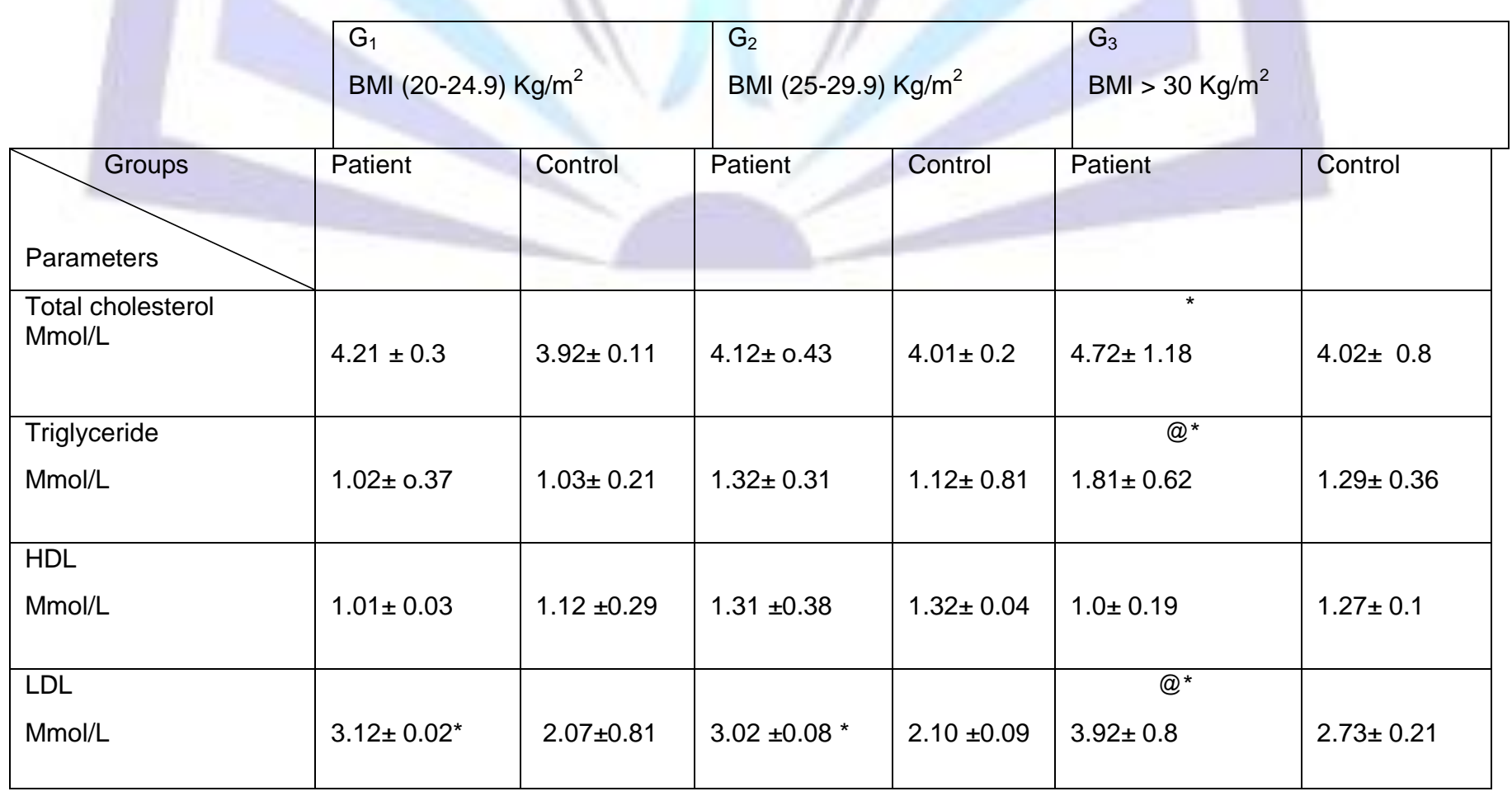


ISSN 2321-807X

\begin{tabular}{|c|c|c|c|c|c|c|}
\hline $\begin{array}{l}\text { VLDL } \\
\text { Mmol/L }\end{array}$ & $0.71 \pm 1.2^{*}$ & $0.49 \pm 0.10$ & $0.70 \pm 0.88$ * & $0.51 \pm 0.13$ & $0.81 \pm 0.36$ & $0.55 \pm 0.17$ \\
\hline IL-33 & & & & & $@^{*}$ & \\
\hline $\mathrm{Pg} / \mathrm{ml}$ & $10.6 \pm 0.22^{*}$ & $14.28 \pm 0.89$ & $19.38 \pm 2.3$ * & $13.7 \pm 1.1$ & $23.72 \pm 2.54$ & $14.3 \pm 1.5$ \\
\hline
\end{tabular}

Significant at $P \leq 0.05$ for patients $G_{3}$ as compared to *Significant at $P \leq 0.05$ when compared to their matching controls $@ \mathrm{G}_{1}$ and $\mathrm{G}_{2}$

Fig (1-3) shows the presence of correlation between BMI and IL-33, in three patient groups

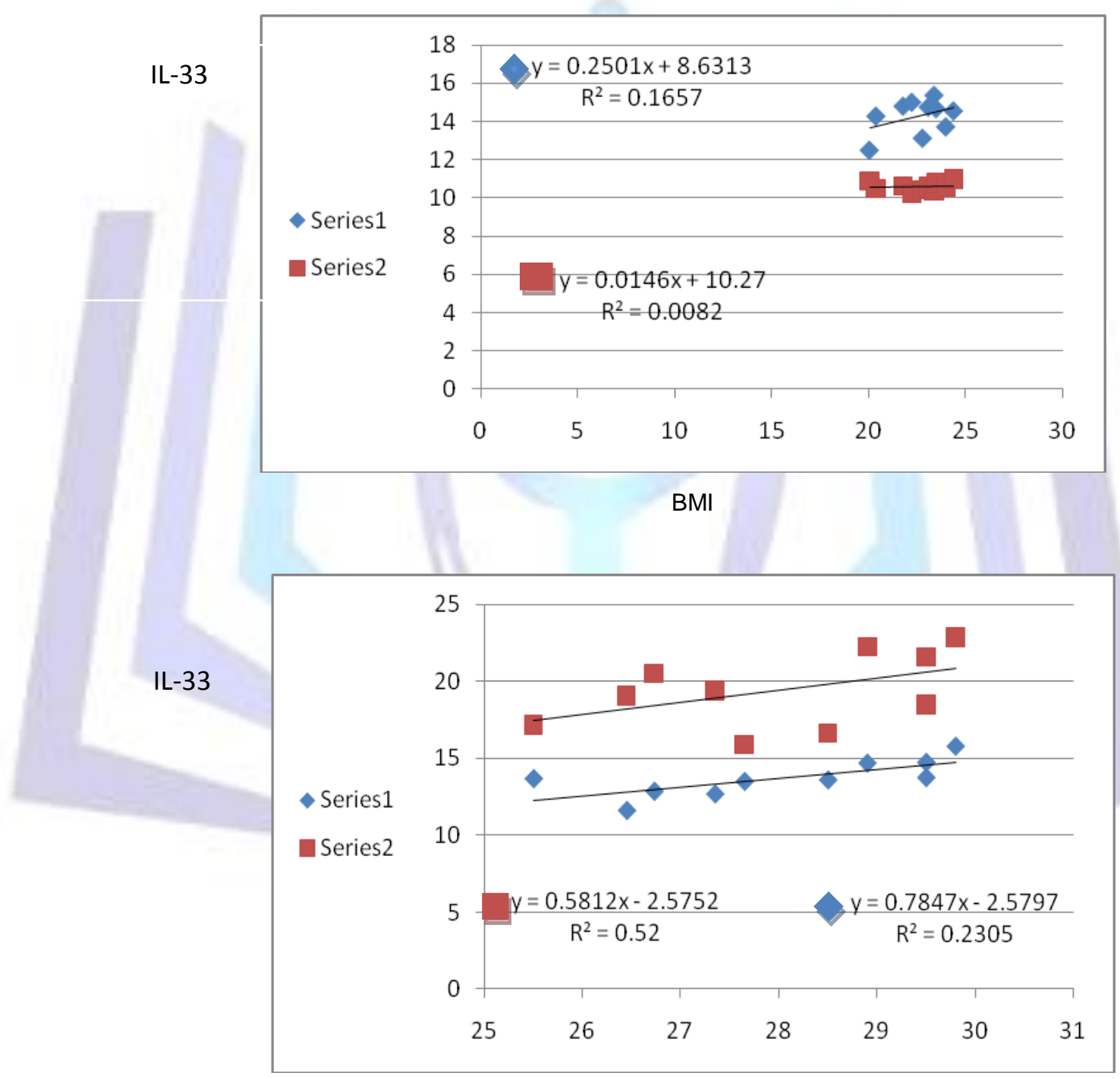

BMI 


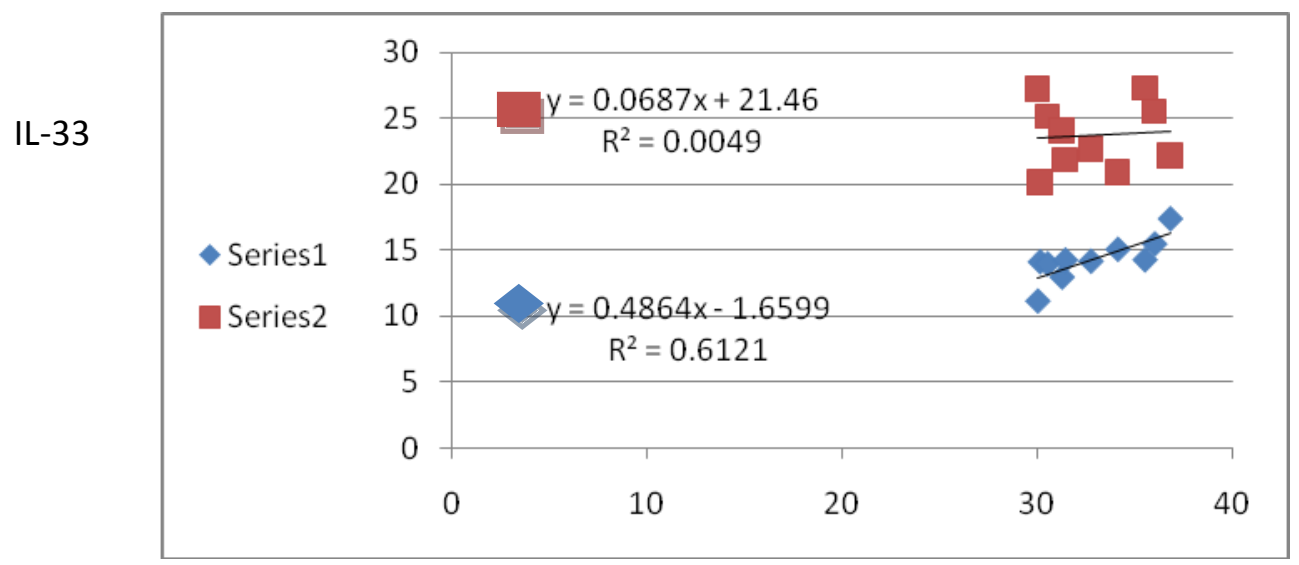

BMI

SERIES 1 : control

SERIES 2 :studied group

\section{DISCUSSION}

From the results of the present study which showed higher levels of IL-33 with higher LDL levels especially in obese patients with cardiovascular disease are consisted with reported date stated that expression of IL-33 and its receptor ST2 human adipose tissue

is

predominantly detectable in endothelial cells and increased by severe obesity indicating an autocrine action. Thus, the adipose tissue microvasculature could participate in obesity-associated inflammation and related complications via IL-33/ST2. [17]. Having entered the vascular wall, atherogenetic lipoprotein particles, such as low-density lipoprotein (LDL) and very low density lipoprotein (VLDL), are retained with the extracellular matrix. This entrapment occurs by the interaction of negatively charged sulphate groups of matrix proteoglycans and positively charged domains of apolipoprotien B-100. LDL particles within the arterial wall are highly susceptible to oxidation and acylation. [18]. In vitro IL-33 has been shown to constrain macrophage foam cell formation by decreasing modified (i.e. acetylated or oxidized; AcLDL or OxLDL) low- density lipoprotein uptake [19].Given these properties, it is conceivable that natural $\operatorname{lgM}$ antibodies play a protective role in atherosclerosis [20].

The expression of ST2L, the membrane-bound form of IL-33 receptor on macrophages, is a sine qua non for this cytokines atheroprotective effects. Actually, in ST2 macrophages that are completely devoid of this receptor protein, IL-33 by itself can neither decrease the uptake of LDL nor reduce intracellular cholesterol levels [19]. This concept is supported by the clinical finding that the IL-33 decoy receptor SST2 was elevated in serum early after acute myocardial infarction (AMI), and correlated with creatine kinase and inversely correlated with left ventricular fraction [21], and elevated levels of sST2 were significant predictor of mortality or future heart failure (HF)[22].Taken together, these studies indicate that sST2 has the potential to be a predictive CV biomarker in patients with acute myocardial infarction( AMI), heart failure( HF) and dyspnea. Thus far, serum or plasma IL-33 has been measured in CV diseases.

In the role of the IL-33/ST2 pathway in inflammatory disease IL-33 was initially found in the nucleus of the high endothelial venules (HEV) of secondary lymphoid tissues (5). More recently, IL-33 expression has been reported in coronary artery smooth muscle cells [23], coronary artery endothelium [24], non-HEV endothelial cells [25], adipocytes [26] and cardiac fibroblasts suggesting that IL-33 may play a role in various CV disorders [27].

Binding of IL-33 to theST2 receptor, in response to cardiac disease or injury, such as an ischemic event, elicits a cardioprotective effect resulting in preserved cardiac function. This cardioprotective IL-33 signal is counterbalanced by the level of soluble ST2, which binds IL-33 and makes it unavailable to the ST2 receptor for cardioprotective signaling. As a result, the heart is subjected to greater stress in the presence of high levels of soluble ST2. [28][29]

The biological effects of IL-33 are limited by a soluble decoy from ST2 (sST2). Recent studies indicate a protective role for IL-33 and ST2L in atherosclerosis, obesity and cardiac remodeling. [30]

In addition to its potential as a biomarker for adverse cardiovascular events, ST2 is considered to play a causal role in chronic cardiovascular diseases such as atherosclerosis and heart failure. Signaling of IL-33 via ST2 has been shown to be cardioprotective in mouse models of myocardial infarction, heart transplantation and cardiac hypertrophy and fibrosis. Furthermore, treatment with IL-33 reduced the development of plaques in atherosclerotic mice. [31]

IL-33 has been also found to have protective effects in cardiovascular diseases. Recent studies have illustrated that IL-33 attenuates cardiac fibrosis induced by increased cardiovascular load in mice (transaortic constriction). Since cardiac fibrosis is largely dependent on increased production of extracellular matrix by cardiac fibroblasts, we hypothesized that IL-33 directly inhibits pro-fibrotic activities of these cells. [32] 
Clinically, in patients with symptomatic heart failure(HF), elevated concentration of SST2 are strongly associated with severity of the diagnosis, and powerfully predict increased risk of complications, independent of other established or emerging biomarkers. Soluble ST2(sST2) testing has been shown to predict onset of symptomatic HF in patients with acute myocardial infarction, while in community-based subjects, SST2 values independently predict future HF, cardiovascular disease events, and mortality. [33]

\section{CONCLUSION}

A conclusive remark could be stated that the work on IL-33 is still in the beginning and extensive studies are needed to elucidate the exact role of this cytokine in obesity and atherogenic lipoprotein and their metabolic consequences in predicting cardiovascular diseases.

\section{REFERENCES}

[1] McGill H.C., McMahan C.A., Gidding S.S. 2008. Preventing heart disease in the 21st century implications of the Pathobiological Determinants of Atherosclerosis in Youth (PDAY) study. Circulation Mar; 117 (9): $1216-27$.

[2] Smith A.F., Beckett G.J., Walker S.W and Rae P.H. 2003. Lecture notes on Clinical Biochemistry, $6^{\text {th }}$ ed. The Blackwell Science 10:136-148.

[3] Fulton J.S. 2001. Care considerations for the client who is obes, Clinical Nurse Specialist 15(5):217-218.

[4] Flier J.S., Maratos-Flie E. 2005. Obesity. In: Kasper D.L. Harrisons Principles of International Medicine, $16^{\text {th }}$ ed. USA. McGraw- Hill companies 64:422-430.

[5] Backkevold E.S., Roussigne M.,Yamanaka T.,Johansen F. E.,Jahnsen F.L.,Amalric F.,Brandtzaeg P., Erard M., Haraldsen G.and Girard J.P.2003. Molecular characterization of NF-HEV, a nuclear factor preferentially expressed in human high endothelial venules. Am.J. Pathol., 163(1), 69-79.

[6] Pavel K., Zdenka H.,Martina K. and Jan K.2012. Paradoxes and Pitfalls of Intrleukin-33 in Atheroeclerosis. The Open Clinical Chemistry Journal, 5, 13-20.

[7] Ashley, M. Miller 2012. Role of IL-33 in inflammation and disease. Journal of Inflammation. 8:22.

[8] U-CyTech biosciences 2011

[9] Kurowska S.M., Hueber A., Stolarski B. and Mclnnes 2011. Interleukin-33: A novel mediator with a role in distinct disease pathologies. J. Inter. Med. 269(1); 29-35.

[10] Richmond W. 1974. Proceding in the development of an enzymatic technique for the assay of cholesterol in biological fluids.Clin.scc.Mol.Med:46; 6-7.

[11] Fassti P. and Prencipe L. 1982. Measurement of triglyceride calorimetrically with an enzyme that produce $\mathrm{H}_{2} \mathrm{O}_{2}$. Clin.Chem.25 (10); 2077-2080.

[12] Burstein M., Scolink H.R., and Morfin R.1970. Measurement of HDLc in the plasma with a sensitive colorimetric method. J. Lipid Res.:19; 583-589.

[13] Friedwald W. T., Kevy R. L. and Fredikson D. S.1972. Estimation of the concentration of LDL in plasma without use of preparative ultracentrifugation. Clin. Chem.:18; 499-502.

[14] RayBio® Human IL-33 Elisa Kit Protocol.

[15] Eknoyan, Garabed 2007. Adolphe Quetelet (1796-1874)—the average man and indices of obesity. Nephrology Dialysis Transplantation 23 (1): 47-51.

[16] Fost L., Hane L.J. and Vestergard P. 2005.Overweight and obesity as risk factors of a trial fibrillation or fluter. The Danish diet; Am.J. of $17^{\text {th }}$ ed: $118 ; 489-495$.

[17] Zeydal M., Wemlyl B., Demyanets S., Kaun C., Ha mmerle M., Hantusch B., Schranz M., Neuhofer A., Itariul B.K., Keck M., Prager G., Wojta J. and Stulnig J. 2013. Sever obesity increases tissue expretion of interlukine-33 and its receptor ST2, both predominantly detectable in endothelial cells of human adipose tissue. International Journal of Obesity 37. 658-665.

[18]- Crundtman, C.,Wick, G. 2011. The autoimmune concept of atherosclerosis. Curr.Opin.Lipidol. 22(5), $327-334$.

[19]- McLaren J. E., Michael D. R., Salter R. C., Ashlin,T. G., Cader, C. J., Miller, A. M., Liew, F.Y. and Ramji D. P. 2010. IL-33 reduces macrophage foam cell formation. J. Immunol. 185(2), 1222-1229.

[20]-Binder,C.J.,Shaw P.X.,Chang M.K.,Boullier,A.,Hartvigsen K.,Hokko S.,Miller Y.I.,Woelkers D.A.,Corr M.,Witztum J.L.2005. The role of natural antibodies in atherogensis. J. Lipid Res.46 (7), 1353-1363. 
[21]-Weinberg E.O., Shimpo M., De Keulenaer G.W., MacGillivray C., Tominaga S., Solomon S.D., Rouleau J.L., Lee R.T. 2002. Expression and regulation of ST2, an interleukin-1 receptor family member, in cardiomyocytes and myocardial infarction. Circulation 106:2961-2966.

[22]- Shah R.V. and Januzzi JL Jr 2010.ST2: a novel remodeling biomarker in acute and chronic heart failure.Curr. Hrart Fail Rep. Mar;

$7(1): 9-14$.

[23]- Schmitz J., Owyang A., Oldham E., Song Y., Murphy E., McClanahan T.K., Zurawski G., Moshrefi M., Qin J., Li X., et al. 2005. IL-33, an interleukin-1-like cytokine that signals via the IL-1 receptor-related protein ST2 and induces T helper type 2-associated cytokines. Immunity 23:479-490.

[24]- Bartunek J., Delrue L., Van Durme F., Muller O., Casselman F., De Wiest B., Croes R., Verstreken S., Goethals M., de Raedt H., et al. 2008. Nonmyocardial production of ST2 protein in human hypertrophy and failure is related to diastolic load. J Am Coll Cardiol 52:2166-2174.

[25]- Kuchler A.M., Pollheimer J., Balogh J., Sponheim J., Manley L., Sorensen D.R., De Angelis P.M., Scott H., Haraldsen G. 2008. Nuclear interleukin-33 is generally expressed in resting endothelium but rapidly lost upon angiogenic or proinflammatory activation. Am J Pathol. 173:1229-1242.

[26]- Saidi S., Bouri F., Lencel P., Duplomb L., Baud'huin M., Delplace S., Leterme D., Miellot F., Heymann D., Hardouin P., et al. 2011. IL-33 is expressed in human osteoblasts, but has no direct effect on bone remodeling. Cytokine 53:347-354.

[27]- Sanada S., Hakuno D., Higgins L.J., Schreiter E.R., McKenzie A.N., Lee R.T. 2007. IL-33 and ST2 comprise a critical biomechanically induced and cardioprotective signaling system. J Clin Invest 117:1538-1549.

[28]- Ky B., French B., McCloskey K., Rame J.E., Mclntosh E., Shahi P., Dries D.L., Tang W.H., Wu A.H., Fang J.C., Boxer R., Sweatzer N.K., Levy W.C., Goldberg L.R., Jessup M., Cappola T.P. 2011. High-sensitivity ST2 for prediction of adverse outcomes in chronic heart failure. Circ Heart Fail, Mar; 4(2):180-7.

[29]- Socrates T., deFilippi C., Reichlin T., Twerenbold R., Breidhardt T., Noveanu M.,Potocki M., Reiter M., Arenja N., Heinisch C., Meissner J., Jaeger C.,Christenson R., Mueller C. 2010. Interleukine family member ST2 and mortality in acute dyspnoea. J. Intern. Med. Nove; 268(5):493-500.

[30]- Ashley M.Miller and Foo Y. Liew 2011. The IL-33/ST2 pathway- A new therapeutic target in cardiovascular disease. Pharmacology and Therapeutics, 131(2), 179-186.

[31]- Willems S., Hoefer I., and Pasterkamp G. 2012. The role of the Intrleukin 1 receptor-like (ST2) and Interleukin-33 pathway in cardiovascular disease and cardiovascular risk assessment. Minerva Med., Dec; 103(6):513-24.

[32]- Zhu J.and Carver W. 2012.Effects of interleukin-33 on cardiac fibroblast gene expression and activity. US National Library of Medicine National Institutes of Health. Cytokine. Jun; 58(3):368-79.

[33]- Januzzi J.L.Jr.2013. ST2 as a cardiovascular risk biomarker: from the bench to the bedside. J. Cardiovasc Transl Res. Aug; 6(4):493-500. 